\title{
O envelhecimento no Brasil: aspectos sociais, políticos e demográficos em análise
}

\author{
Aging in Brazil: social, political and \\ demographic aspects under analysis
}

Silvana Maria Escorsim
(1) https://orcid.org/0000-0002-4240-1692

Resumo: $\mathrm{O}$ artigo discute o fenômeno do envelhecimento da sociedade brasileira, a partir das relações antagônicas das classes sociais no capitalismo. Situa a dependência da classe trabalhadora às políticas públicas e sociais no envelhecimento. A revisão bibliográfica referencia a legislação de proteção social e analisa os dados sociodemográficos. O acesso a essas políticas possibilitou a melhoria nas condições de vida dos idosos, tendência que se reverteu a partir da contrarreforma neoliberal do Estado.

Palavras-chave: Idosos. Proteção Social. Dados Sociodemográficos.

\begin{abstract}
The article discusses the phenomenon of the aging of Brazilian society, based on the antagonistic relations of social classes in capitalism. It situates the dependence of the working class on public and social policies in aging. The bibliographic review references the social protection legislation and analyzes the socio-demographic data. Access to these policies made it possible to improve the living conditions of the elderly, a trend that was reversed from the neoliberal counterreform of the State.
\end{abstract}

Keywords: Seniors. Social Protection. Sociodemographic Data. 


\section{Introdução}

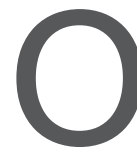

debate sobre o envelhecimento populacional segue duas grandes vertentes: a primeira considera os avanços científicos e tecnológicos que ampliam a longevidade dentro de um processo natural do ciclo de vida; e uma segunda que o situa nos marcos dos contextos sócio-históricos, políticos e econômicos das sociedades analisadas e, desse modo, desnaturaliza-se a ideia de que o envelhecimento ocorre de modo linear e homogêneo. Este artigo pauta a análise desse fenômeno social a partir da segunda vertente. Ainda mais, considera que o processo de envelhecimento polariza-se nas relações de classe, ou seja, o envelhecimento da classe trabalhadora é profundamente desigual ao da classe burguesa, em se tratando de uma sociedade capitalista, como é o caso brasileiro.

Admitindo-se que a propriedade privada dos meios de produção constitui o marco divisor entre os membros da sociedade em dois grupos fundamentais, ou seja, proprietários e não proprietários dos meios de produção, esta condição é estruturante das classes sociais, cujos interesses passam a ser imediatamente antagônicos. Considerando-se que as relações de produção/reprodução são constitutivas da sociedade, necessárias para a manutenção da vida, também, faz-se necessária a existência de um conjunto de instituições sociais, de ideias e sociabilidades que lhes deem significado e sustentação ideopolítica na estrutura social capitalista, a qual resulta dessas relações.

Em sua obra, Marx e Engels (2010) identificaram nas sociedades industriais capitalistas o surgimento de uma classe burguesa ${ }^{1}$ proprietária dos meios de produção. $O$ capital investido por ela é valorizado mediante a extração de um sobretrabalho não pago aos trabalhadores, os quais são obrigados a vender sua força de trabalho para sobreviver, visto ser

1 Por burguesia entende-se a classe dos capitalistas modernos, proprietários dos meios de produção social que empregam o trabalho assalariado. Por proletariado, a classe dos assalariados modernos que, não tendo os meios próprios de produção, são obrigados a vender sua força de trabalho para sobreviver (Nota de F. Engels à edição inglesa de 1888) (Marx; Engels, 2010, p. 40). 
a única riqueza que possuem. Estabeleceu-se, desde então, uma antagônica relação entre as classes. "A história de todas as sociedades até hoje existentes é a história das lutas de classes" (Marx; Engels, 2010, p. 40).

Na contemporaneidade, Antunes (2001) cunha a expressão classe-que-vive-do-trabalho, no sentido de ampliar e enfatizar o atual sentido da classe trabalhadora como ser social que trabalha. Para o autor, a classe-que-vive-do-trabalho inclui a totalidade daqueles que vendem a sua força de trabalho, tendo como núcleo central os trabalhadores produtivos (manuais ou não), visto que deles se extrai diretamente a mais-valia por sua participação direta no processo de valorização do capital. A expressão agrega os trabalhadores improdutivos, cujo trabalho é consumido como valor de uso e não como trabalho que cria valor de troca. Defende que uma noção contemporânea deve incorporar a totalidade dos trabalhadores assalariados, vista a crescente imbricação entre trabalho produtivo e improdutivo no atual estágio capitalista.

Essa noção incorpora o proletariado precarizado, o subproletariado moderno, part time, o novo proletariado dos McDonald's, os trabalhadores hifenizados de que falou Beynon, os trabalhadores terceirizados e precarizados das empresas liofilizadas de que falou Juan José Castillo, os trabalhadores assalariados da chamada "economia informal", que muitas vezes são indiretamente subordinados ao capital, além dos trabalhadores desempregados, expulsos do processo produtivo e do mercado de trabalho pela reestruturação do capital e que hipertrofiam o exército industrial de reserva, na fase de expansão do desemprego estrutural (Antunes, 2001, p. 103-104).

É a partir desta tensa e contraditória configuração da vida social para os trabalhadores que a velhice se situa, como tempo de construir histórias singulares e histórias universais, cuja situação de classe perpassa a condição de existência, e não permite que seja vislumbrada de modo uniforme e homogêneo. Existem muitos modos de envelhecer, todavia enraizados em dois fundamentais, os quais se constituem a partir da divisão de classe social entre burguesia e proletariado. 
Os levantamentos sociodemográficos sobre o perfil do envelhecimento no Brasil só adquirem inteligibilidade política se explicados a partir dessas relações de classe, pois é a classe trabalhadora que depende visceralmente das políticas de trabalho e renda e das políticas de proteção social, em especial, Saúde, Previdência e Assistência Social. Desse modo, as condições objetivas e subjetivas (sociabilidades) para envelhecer estão atreladas ao acesso a que possam ter os trabalhadores frente às políticas redistributivas, e os resultados das pesquisas demonstram o quanto o país promove ou não justiça e equidade social no sentido de diminuir as desigualdades sociais.

O contexto político e econômico incide diretamente no modo como se vive e como se envelhece. Assim, o presente artigo objetiva analisar os indicadores do envelhecimento sob o prisma de classe social, fundamentalmente, o da classe trabalhadora. Para tanto, o suporte metodológico bibliográfico utilizou-se dos levantamentos sociodemográficos das pesquisas do Instituto Brasileiro de Geografia e Estatística (IBGE) e do arcabouço normativo-jurídico que prescreve a proteção social à pessoa idosa.

\section{Debates sobre o envelhecimento}

Para compreender a velhice é necessário contextualizá-la no marco das relações sócio-históricas, políticas e econômicas do país, entendendo-a como um processo que está envolto em condições objetivas (materiais) e subjetivas (sociabilidades) para a sua materialização cotidiana.

O processo de envelhecimento extrapola a condição de mero ciclo biológico condicionado no tempo para ser entendido como fenômeno humano e social, multifacetado por expressões sociais e múltiplas significações culturais construídas na sociedade, que só adquirem inteligibilidade quando pensadas a partir de um determinado modo de produção, neste caso, o modo de produção capitalista. Nessa direção, é possível entender o lugar social dos membros de uma sociedade a partir de suas posições 
diante dos meios de produção fundamentais existentes, calcados na propriedade privada destes.

Teixeira (2010) problematiza o envelhecimento a partir dos determinantes econômicos, políticos e culturais que forjam a ordem e o tempo do capital. Desvelar esses determinantes possibilita descortinar que o envelhecimento do trabalhador tensiona-se numa problemática social, visto seu pertencimento a uma classe social destituída dos meios de produção e de renda advinda da riqueza socialmente produzida. A classe trabalhadora, ao envelhecer, perde o valor de uso para o capital, cuja lógica de acumulação é estruturalmente geradora das desigualdades sociais, expressas na pobreza, no desemprego e no aumento da população excedente.

Essas desigualdades sociais são reproduzidas e ampliadas no envelhecimento do trabalhador, geralmente, para os trabalhadores pobres, cuja trajetória foi marcada por piores condições de vida e trabalho, que tiveram suas necessidades sociais rebaixadas, submetidas a mínimos sociais para sua sobrevivência e de sua família (Teixeira, 2010 p. 67).

No campo da produção científica sobre o envelhecimento, Bezerra, Almeida e Therrien (2012) procederam a uma análise sobre as produções acadêmicas na área da saúde e constaram que os estudos sobre as consequências do envelhecimento nos países em desenvolvimento eram escassos e centravam-se nos processos relacionados às condições de saúde, questões relacionadas às aposentadorias e aos arranjos familiares, motivados pelo aumento da população acima dos 60 anos.

$\mathrm{O}$ estudo das autoras registrou um aumento significativo desta temática nas publicações no período de 2006 a 2009, cujo foco explicativo centrava-se na transição demográfica registrada nos países em desenvolvimento, contudo, sem oferecer uma análise sociopolítica e econômica deste processo. Neste cenário, a aprovação no Brasil do Estatuto do Idoso (Brasil, 2003a) teria fomentado o interesse nas pesquisas de graduação e pós-graduação. Os artigos estudados evidenciavam que os serviços de 
saúde seriam pressionados para atender a uma demanda crescente nos procedimentos diagnósticos e terapêuticos para as doenças crônicas não transmissíveis e neurodegenerativas. Consequentemente, o atendimento a essa população exigiria o investimento governamental nos serviços voltados para a reabilitação física e mental (Bezerra; Almeida; Therrien, 2012).

As pesquisas nas áreas da reabilitação dos idosos são necessárias, contudo, os indicadores epidemiológicos e suas análises, por vezes, são demonstrados quantitativamente e de modo descontextualizado das relações sociais estruturais da sociedade que os produziram.

Nos estudos acadêmicos sobre o envelhecimento, não é incomum que as características evolutivas desse ciclo vital sejam apresentadas como um processo uniforme que, em tese, explicaria o fenômeno para toda e qualquer população, sem se considerar as condições objetivas e subjetivas de existência. ${ }^{2}$ Estas últimas demarcam as singularidades da vida social, em particular para a classe trabalhadora, cujo vigor é subtraído desde a mais tenra juventude para o provimento da vida, muitas vezes, de modo precarizado e desprotegido perante as políticas sociais, haja vista a quantidade de trabalhadores na condição de informalidade no Brasil. A classe trabalhadora tem sua força de trabalho expropriada e explorada frente às condições de produção e reprodução social, tendo como principal substrato o seu tempo de vida.

Nessa direção, a narrativa utilizada em inúmeras propostas de trabalho social com idosos é o aprendizado para envelhecer com qualidade de vida, submetendo-os ao controle de comportamentos adversos às reais experiências de vida e de subsistência, muitas vezes, relegadas a mínimos sociais. Estas propostas esvaziam-se de sentido por ocultar as contradições e os conflitos existentes na ordem do capital, no que se refere às condições objetivas da classe trabalhadora em ter satisfeitas as suas necessidades humano-sociais.

2 Haja vista os discursos sobre o envelhecimento ativo com vista à preservação das capacidades, como endosso para a longevidade com suposta saúde e qualidade de vida (Assis; Avanci, 2010). 
O significado social sobre o processo de envelhecimento humano assume diferentes concepções em se tratando de contextos sócio-históricos e políticos, em sociedades determinadas, como o caso brasileiro. Nesse sentido, pode-se afirmar que esse processo condiciona-se a partir de relações sociais que demarcam o valor social que será atribuído a determinados grupos e segmentos, a partir do lugar ocupado na sociedade e do grau de importância no processo produtivo e reprodutivo da sociedade, tendo em vista o valor de uso para o capital.

Na sociedade capitalista, cujos valores encontram-se amalgamados nas relações de competitividade, do individualismo, do culto à juventude e à boa forma e, especialmente, na naturalização da desigualdade social, a velhice simboliza um antagonismo à ideologia dominante. Esta última advém das concepções burguesas de mundo, acirradas na contemporaneidade pelas relações econômicas e sociais da sociedade capitalista madura, que se baseia no efêmero, na transitoriedade de pessoas e coisas, na intensa acumulação e apropriação privada da riqueza socialmente produzida pela classe abastada, num mundo onde as relações são desumanizadas.

Segundo Haddad (1993), há uma ideologia do envelhecimento para a qual é atribuído o sentido de "ciclo natural da vida", porém, descolado do contexto político, social e econômico vigente, como se as classes sociais e suas relações antagônicas não interferissem diretamente no processo de viver e envelhecer. Esta visão naturalizadora da velhice ignora a divisão de classes, que implica as condições objetivas de existência destas e colocam-se como determinantes para as experiências cotidianas e na construção da história de grupos e coletivos.

Isso se traduz no modo como se vive e se envelhece, pois, dependendo das condições econômico-sociais, pode haver uma intensificação do processo de penúria das condições objetivas e subjetivas de vida ou interrupção prematura da existência devido às iniquidades sociais, tais como a miséria, a pobreza, a fome, as doenças, a negligência familiar e o abandono social. Falar de envelhecimento pressupõe descortinar que há 
maneiras diferentes de viver e de morrer, que não se envelhece de um único modo (Haddad, 1993), visto que não há homogeneidade neste processo.

O envelhecimento reflete o modo como se viveu da infância à vida adulta. Se as condições objetivas e subjetivas de vida possibilitaram suprir as necessidades físicas, psíquicas e sociais de indivíduos e grupos, certamente, estes conseguirão alcançar maior longevidade, a qual pode ser desfrutada com mais saúde e satisfação pessoal. Contudo, o inverso é verdadeiro, na insuficiência de atendimento às condições essenciais à vida, a condição de penúria acentua o sofrimento físico e psíquico, o que pode resultar na interrupção prematura da existência.

\section{A proteção legal para a pessoa idosa}

No Brasil, estima-se que a população idosa tenha alcançado a marca de 30,2 milhões de pessoas (IBGE, 2017). Isso representa um avanço social em termos do aumento da expectativa de vida e expressa uma significativa melhoria nas condições de vida desse segmento social, ainda que as desigualdades sociais existentes nas diferentes regiões brasileiras, os preconceitos e as discriminações persistam nas esferas públicas e privadas. Apesar disso, os idosos conquistaram mais espaços sociais e políticos, e contribuem com o desenvolvimento econômico e cultural do país.

Essas conquistas sociais não se deram ao acaso, elas foram frutos das intensas lutas históricas que os trabalhadores engendraram em seu percurso de vida e conquistaram a partir de sua vocalização nos espaços políticos, seja no campo dos direitos humanos, seja nos direitos sociais e políticos. Em países cuja história das lutas sociais dos trabalhadores alcançou estágios mais avançados na sua organização, a questão do envelhecimento conquistou pauta na agenda estatal nos últimos três decênios do século passado.

Internacionalmente, o debate sobre o envelhecimento ganhou destaque na I Assembleia Mundial sobre o Envelhecimento organizada 
pela Organização das Nações Unidas em 1982 (Brasil,2003b). Nesse encontro, definiu-se que a velhice teria como marco 65 anos nos países desenvolvidos e 60 nos países em desenvolvimento. A expectativa de vida passou a ser considerada um dos indicadores que demonstram índices de desigualdade entre países.

A II Assembleia Mundial sobre o Envelhecimento, ocorrida em Madri em 2002 (Brasil, 2003b), constatou o acelerado crescimento no número de idosos no mundo, em particular nos países em desenvolvimento, e concluiu pelo necessário protagonismo desse segmento junto às ações governamentais, decorrentes da responsabilidade estatal frente às políticas públicas, que resultem no desenvolvimento dos países.

O marco legal para o reconhecimento da cidadania e dos direitos sociais no Brasil é a Carta Constitucional de 1988 (Brasil, 1988). Na Carta Magna, ratificou-se a garantia dos direitos sociais a esse segmento populacional no capítulo da Seguridade Social, no que diz respeito à expansão da rede de proteção, reconhecendo a Assistência Social como política integrante da proteção social, porém, esta só seria regulamentada após dois anos.

Foi através das legislações infraconstitucionais que a pessoa idosa conquistou paulatinamente destaque e obteve o reconhecimento efetivo de seus direitos sociais. Com a promulgação da Lei Orgânica da Assistência Social (Brasil, 1990), a LOAS em seu artigo $2^{\circ}$ previu o Benefício de Prestação Continuada e, neste, o idoso em situação de pobreza que comprove a incapacidade para prover a sua subsistência obteve o direito de receber o benefício assistencial no valor de um salário mínimo.

A Política Nacional do Idoso (Brasil,1994) constitui-se na primeira legislação específica para esse segmento social no Brasil. Com ela, a população idosa obteve a prescrição de seus direitos sociais, no sentido da promoção de sua autonomia e participação social (Brasil, 2014). Após cinco anos, a Política de Saúde estabeleceu a prevenção e a promoção da saúde por intermédio de atendimento multidisciplinar às demandas dessa população a partir do pacto pela vida, com destaque para o idoso, 
a princípio pela Portaria Ministerial n. 1.395/99 (Brasil, 1999) e depois instituindo a Política Nacional de Saúde da Pessoa Idosa (Brasil, 2006).

Outra conquista de significativa relevância social efetivou-se na promulgação do Estatuto do Idoso (Brasil, 2003a), o qual ratificou direitos já firmados por outras políticas públicas. A inovação trazida pelo Estatuto deu-se na garantia do atendimento prioritário na saúde e na assistência social, assim como na necessidade de programas educacionais que pudessem promover a autonomia dos seus assegurados. Outro aspecto a ser destacado diz respeito à questão da violência sofrida pelos idosos, a qual comparece destacada nos artigos $2^{\circ}$ e $3^{\circ}$ da Lei, cujo entendimento a circunscreve no campo da violação dos direitos e, assim, prescreve sanções aos transgressores (Brasil, 2014).

Todo esse arcabouço jurídico-normativo tem a função de amparar, proteger e promover o acesso e a garantia da população idosa a serviços e benefícios das políticas públicas, como também reconhecer suas plenas capacidades sociopolíticas, ratificando-as como direitos de cidadania.

\section{O cenário sociodemográfico do envelhecimento no Brasil. Repercussões sociais e políticas}

A configuração do envelhecimento da população brasileira tem sido estimada pelas pesquisas demográficas dos institutos governamentais. A Pesquisa Nacional por Amostra de Domicílios (PNAD) (IBGE, 2012) apurou que a população idosa acima dos 60 anos estava assim distribuída no Brasil: mulheres - 13.840.000; e homens - 11.010.000. O censo do IBGE (2010) também registrou na época quase 30.000 pessoas centenárias.

Segundo a PNAD (IBGE, 2017), o segmento de idosos teve um incremento de $18 \%$ nesse grupo etário. 0 número de mulheres foi estimado em 16,9 milhões (56\% do total de idosos) e de homens em 13,3 milhões (44\% do grupo). A quantidade cresceu em todas as unidades da federação, sendo os Estados do Rio de Janeiro e do Rio Grande do Sul os que 
possuem o maior número de idosos. O Amapá apareceu como o Estado com o menor percentual (7,2\%).

Para a Secretaria de Direitos Humanos da Presidência da República (Brasil, 2014), a expectativa de vida do brasileiro aumentou em média para 74,08 anos; esse dado foi identificado em 2011, reafirmando a ideia de que esse segmento social é o que mais cresce no Brasil. Após o Censo de 2010 , houve um incremento de $47,8 \%$ nas faixas etárias acima dos 80 anos (IBGE, 2012).

Outro fenômeno destacado pela PNAD (IBGE, 2017) foi o aumento na autodeclaração de pretos e pardos no período entre 2012 e 2017. Os dois grupos cresceram consideravelmente: os que se declararam pretos foram de $7,4 \%$ para $8,6 \%$; os pardos de $45,3 \%$ para $46,8 \%$.

Há uma projeção de que em 2025 o país ocupará o $6^{\circ}$ lugar no ranking de maior população idosa no planeta. A PNAD (IBGE, 2012) também identificou uma feminilização do envelhecimento em virtude de que as mulheres vivem, em média, sete anos a mais que os homens. Outro aspecto levantado por essa pesquisa foi o aumento de pessoas idosas vivendo sozinhas no domicílio, representando mais de 6,7 milhões. Enquanto o idoso dispuser de suas capacidades físicas e emocionais para sua autonomia, poderá realizar todas as atividades cotidianas da vida diária. Contudo, o avanço da idade repercute na diminuição progressiva das capacidades funcionais, o que também indica que haverá cada vez mais a necessidade de cuidadores, familiares ou não, qualificados para suprir as demandas nos cuidados com alimentação, higienização, auxílio na administração medicamentosa, conforto e segurança do idoso.

Esses dados refletem uma mudança no quadro epidemiológico brasileiro. A ampliação do sistema de saneamento básico (ainda que esteja longe da cobertura integral) e a educação para a saúde contribuíram para o sucesso na prevenção e na diminuição de riscos e agravos para as doenças infectocontagiosas. $\mathrm{O}$ aumento da longevidade populacional demarcou novos desafios para a saúde, pois se houve um declínio dos adoecimentos por doenças infectocontagiosas, identificou-se um incremento 
das taxas para as doenças crônico-degenerativas não transmissíveis que estão entre as mais prevalentes para a população idosa.

Esse cenário coloca em xeque a capacidade do sistema de saúde em responder com programas de prevenção à saúde para enfermidades cujo desenvolvimento é lento e gradativo, sem reversão, exigindo qualificação técnica de mão de obra nessa área e recursos técnico-financeiros para ampliar o número de atendimentos nos equipamentos de saúde que possam garantir a integralidade dos cuidados dispensados em todos os níveis de complexidade do sistema.

Os dados levantados pela PNAD (IBGE, 2012) apontaram para um incremento na renda e no consumo das pessoas idosas. Sem dúvida, isso foi propiciado pelas políticas sociais, em especial, através dos benefícios previdenciários e da assistência social, sobretudo para os mais pobres. Como decorrência, esse segmento social assumiu significativa participação na composição da renda total das famílias, na condição de principais provedores ou corresponsáveis, o que ocorre em 53\% dos domicílios brasileiros. Nestes, os idosos comparecem com mais da metade da renda de suas famílias, segundo o levantamento estatístico. Essa renda advém em sua grande maioria dos benefícios previdenciários, como aposentadorias ou pensões. Idosos com 65 anos ou mais que estão nessa condição representam 84,4\% (IBGE, 2010). Nesse aspecto, o levantamento (IBGE, 2012) mostrou que em $27 \%$ dos lares brasileiros, os idosos convivem em famílias intergeracionais. Esse fenômeno pode ser explicado pela necessidade de uma composição das várias rendas dos membros das famílias para a garantia da sobrevivência, tendo em vista que o salário mínimo é a referência nacional de aquisição pecuniária auferida pelo trabalho de muitos brasileiros.

Assim, pode-se afirmar que a sua presença contribui significativamente para a sobrevivência de suas famílias e suas rendas alteram positivamente na circulação econômica dos municípios onde residem. Considerando-se que, em sua maioria, os municípios brasileiros são de pequeno e médio porte, pode-se estimar o impacto social que a presença 
dos idosos deflagra nas economias locais, ainda que persistam os preconceitos e as discriminações sobre o fenômeno da velhice.

A pesquisa por domicílios também identificou que os idosos brasileiros vivem densamente nas regiões urbanas em detrimento das áreas rurais, numa proporção de 21 milhões contra 3,8 milhões (IBGE, 2012). Também houve uma diminuição nas taxas de extrema pobreza desse segmento populacional, 6\% do total (IBGE, 2012), o que foi influenciado pelo acesso à aposentadoria rural e pelo Benefício de Prestação Continuada da Política de Assistência Social.

As pesquisas recentes do IBGE (2019) apontaram que o desemprego aumentou e atingiu a marca de 12,7 milhões de pessoas no Brasil. A taxa de desocupação voltou a subir no trimestre entre novembro de 2018 a janeiro de 2019. Assim, no cômpito de dez anos (de 2005 a 2015), o nível de ocupação dos idosos caiu de $30,2 \%$ para $26,3 \%$, o que indica o crescimento da vulnerabilidade desse grupo etário para o mercado de trabalho, resultante da baixa média de anos de estudo, o que corresponde a 65,5\% dos idosos com apenas o ensino fundamental incompleto inseridos no mercado de trabalho.

A desigualdade social incide significativamente sobre os idosos moradores das áreas rurais, pois a maioria continua trabalhando, mesmo recebendo benefícios de aposentadorias ou pensões, numa taxa de $84,9 \%$ dos 3,8 milhões declarados. Mais de $50 \%$ dessa população não teve acesso à escolaridade ou completou apenas o primeiro ano do ensino fundamental. O censo do IBGE (2010) identificou 32,2\% de idosos nessa situação, o que reitera a prevalência da ocupação em trabalhos braçais e pouco remunerados.

É necessário destacar que a implementação das políticas protetivas no âmbito da seguridade social, firmadas pela Carta Constitucional de 1988 e regulamentadas por legislações infraconstitucionais, bem como as legislações específicas para a população idosa, possibilitou o reconhecimento da cidadania e firmou o compromisso do Estado na garantia de acesso a benefícios, auxílios e serviços no âmbito das políticas públicas. 
Os indicadores sociais e estatísticos demonstraram uma alteração no quadro sanitário, epidemiológico e econômico-social dos idosos nos últimos 30 anos, o que repercutiu no aumento da longevidade com melhores condições de saúde e de existência. Isso se deveu à ampliação do acesso a benefícios, serviços e auxílios das políticas sociais de Saúde e Assistência Social. Contudo, num país de extremas desigualdades sociais, ocasionadas pelo modelo econômico e social neoliberal, o envelhecimento ainda se coloca como um desafio para a classe trabalhadora, principalmente quando agravado por diferenças no interior desta entre os segmentos urbanos e rurais.

O atual contexto sócio-histórico de regressão dos direitos sociais, promovido pela ofensiva conservadora e neoliberal, no âmbito governamental, desencadeado a partir de maio de 2016, já demonstra os seus efeitos. A contrarreforma do Estado vem incidindo na precarização das relações de trabalho e renda, sobretudo nas progressivas propostas (no âmbito normativo) para o enxugamento do financiamento das políticas sociais, tais como a Previdência, a Saúde, a Educação e a Assistência Social.

Os trabalhadores são aqueles que mais se utilizam das políticas públicas e, por isso, serão os mais atingidos, o que afetará sensivelmente as condições objetivas e subjetivas de vida e o envelhecimento digno da população brasileira. Um exemplo disso ocorreu em dezembro de 2016, com a aprovação da Emenda Constitucional n. 95 (Brasil, 2016), que previu o congelamento dos gastos do governo federal por 20 anos, cujo impacto do arrocho fiscal recaiu principalmente nas áreas da saúde e educação, além das demais políticas. Isso se deu à revelia de que o gasto público per capita com a saúde no Brasil já é um dos menores entre os países que possuem um sistema universal equivalente ao SUS, o que significará em curto e médio prazo a inviabilização do sistema, ${ }^{3}$ penalizando ainda mais a população usuária.

3 Por precariedade, falta ou obsolescência de sua infraestrutura. 
No início de 2019, a presidência da república encaminhou à análise do poder legislativo a Proposta de Emenda Constitucional n. 06/2019 (Brasil, 2019), que versou sobre a reforma da previdência social para os trabalhadores da iniciativa privada e servidores públicos. Essa proposta foi aprovada e passou a vigorar a partir de 13 de novembro de 2019. ${ }^{4} \mathrm{As}$ suas principais mudanças residem no aumento do tempo de contribuição (mínimo) de 15 para as mulheres e 20 anos para os homens, ${ }^{5}$ como também na idade mínima para a aposentadoria: homens com 65 anos e mulheres com 62 anos.

$\mathrm{Na}$ regra anterior, os trabalhadores rurais, por exemplo, podiam se aposentar com 60 e e 55 anos, homens e mulheres, respectivamente, com 15 anos de contribuição básica (Brasil, 2019). A reforma aprovada manteve a quinzena como tempo de contribuição mínimo. Os trabalhadores de economia familiar podem se aposentar sem ter contribuído, porém, desde que comprovem 15 anos de atividade rural.

A reforma penalizou todos os trabalhadores, contudo, acirrou ainda mais a desigualdade e a vulnerabilidade dos trabalhadores rurais. As mulheres idosas que, como foi apontado anteriormente, vivem em média sete anos a mais que os homens, serão frontalmente dilapidadas com a reforma, visto que a pensão por morte equivalia a 100\% do valor da aposentadoria. Com as novas regras, a pensão será de $50 \%$ da aposentadoria do falecido, somando-se a ela $10 \%$ por dependente, o que recairá para $60 \%$ do valor, em média. Por exemplo, a pensão só chegará a ser integral se houver cinco dependentes (Brasil, 2019).

Outro aspecto que causou polêmica e debates foi a proposição de mudança do sistema previdenciário. $O$ modelo atual, de repartição simples, prevê a contribuição solidária dos trabalhadores da ativa para manter os benefícios dos aposentados. A proposta inicial da reforma da previdência

Trata-se da Emenda Constitucional n. 103/2019.

O tempo de contribuição mínimo de 15 anos será mantido para os homens, desde que já estejam contribuindo para o Regime Geral da Previdência Social antes da promulgação da EC n 103/2019. 
sinalizava para a adoção do sistema de capitalização (Brasil, 2019), cuja lógica é a de seguro, em que cada trabalhador contribuiria para sua própria aposentadoria e, em tese, esse fundo poderia ser aplicado pelo sistema gestor no mercado financeiro, alçando maior rentabilidade, com vista a um incremento lucrativo para o sistema financeiro. Essa lógica perversa de cunho neoliberal não obteve aprovação do legislativo. Contudo, as alíquotas de contribuição foram alteradas prevendo aumento progressivo sobre as diversas faixas salariais; esse incremento passou a vigorar no primeiro trimestre de 2020.

Não se teve o propósito de aprofundar esses temas, nem é o objetivo deste artigo analisar o cenário da contrarreforma do Estado, contudo, há que se ilustrar as recentes investidas neoliberais na retração dos investimentos do fundo público nas políticas públicas e sociais, com vista à expansão do mercado nas áreas de interesse social. Essas repercussões deverão ser objeto de novos estudos, levantamentos sociodemográficos e de pesquisas que venham a subsidiar o debate de todos os setores progressistas da sociedade, adensando-o ao do segmento do idoso, e que possam fortalecer a luta pela manutenção e garantia dos direitos já firmados, como também ousem avançar na conquista de outros tantos benefícios e serviços sociais, necessários à classe trabalhadora, que promovam justiça e equidade social.

\section{Considerações finais}

Muitas conquistas sociais foram alcançadas pelo protagonismo dos movimentos dos trabalhadores que vocalizaram, na tensa arena política brasileira, suas demandas e necessidades e no interior dos movimentos, o destaque é para as lutas do segmento dos idosos que, gradativamente, alçaram o reconhecimento do Estado para sua cidadania, por meio da Carta Constitucional de 1988 e de outras legislações infraconstitucionais que ratificaram os seus direitos sociais. 
O arcabouço político-jurídico consolidou a luta histórica desse segmento por melhores condições objetivas de vida, contudo, apenas isso não é suficiente para a garantia do acesso e usufruto de benefícios, auxílios e serviços demandados pela população idosa junto às políticas públicas e sociais. Não é incomum no Brasil a violação de direitos dos idosos. Ainda se faz premente que a legislação seja efetivada no cotidiano da sociedade.

A questão central debatida neste ensaio é a condição da classe trabalhadora idosa que vive de salário ou renda pecuniária, seja para aqueles que ainda necessitam vender a sua força de trabalho, seja para a renda obtida através de benefícios previdenciários e da assistência social.

O estudo demonstrou que as políticas de seguridade social possibilitaram um incremento na renda e no consumo das pessoas idosas, e que estas participam decisivamente na composição da renda total das famílias, como também alteram de forma substancial o cenário econômico dos municípios onde vivem, ainda que, em sua maioria, a população idosa tenha apenas o nível fundamental de escolaridade.

A desigualdade social acentua-se para os idosos que vivem nas áreas rurais, cujas taxas de extrema pobreza persistem. Assim, as políticas de trabalho e renda, bem como as políticas de proteção social, são essenciais para que o processo de envelhecimento seja amparado por condições objetivas que supram as necessidades dos idosos, num momento de declínio ou perda da capacidade laborativa e, desse modo, do seu próprio sustento e manutenção, além de incentivar que a sociedade desenvolva sociabilidades mais humanas e fraternas. Contudo, a profunda desigualdade social brasileira afeta todos os extratos da classe trabalhadora e mais drasticamente a população idosa, quando não lhe assegura os direitos prescritos nas diversas legislações e precariza as condições de existência, como se verifica na atual conjuntura de regressão do financiamento estatal para as políticas públicas e sociais.

Faz-se necessário que a classe trabalhadora se engaje na resistência e no combate ao modelo neoliberal/mercantilista de Estado, com vista 
à ampliação das garantias sociais, políticas e econômicas, para além daquelas já afiançadas legalmente, fortalecendo a democracia e a cidadania, com mais dignidade e saúde em seu processo de envelhecimento.

\section{Referências}

ANTUNES, R. Os sentidos do trabalho: ensaio sobre a afirmação e a negação do trabalho. 5. ed. 4. reimp. São Paulo: Boitempo, 2001.

ASSIS, S. G.; AVANCI, J. Q. É possível prevenir a violência? Refletindo sobre risco, proteção, prevenção e promoção da saúde. In: NJAINE, K.; ASSIS, S. G.; CONSTANTINO, P. (org.). Impactos da violência na saúde. 2. ed. Rio de Janeiro: Fundação Oswaldo Cruz; Educação a Distância da Escola Nacional de Saúde Pública Sergio Arouca, 2010. p. 79-104.

BEZERRA, F. C.; ALMEIDA, M. I. de; THERRIEN, S. M. N. Estudos sobre o envelhecimento no Brasil: revisão bibliográfica. Revista Brasileira de Geriatria e Gerontologia, Rio de Janeiro, v. 15, n. 1, p. 155-167, 2012.

BRASIL. Constituição da República Federativa do Brasil. Brasília: Presidência da República, 1988. Disponível em: http://www.planalto.gov.br/ccivil_03/constituicao/ constituicaocompilado.htm. Acesso em: 20 mar. 2019.

BRASIL. Lei n. 8.742, de 7 de dezembro de 1990. Lei Orgânica da Assistência Social. Dispõe sobre a organização da Assistência Social e dá outras providências. Brasília, 1990. Disponível em: http://www.planalto.gov.br/ccivil_03/leis/L8742compilado.htm. Acesso em: 21 mar. 2019.

BRASIL. Lei n. 8.842, de 4 de janeiro de 1994. Política Nacional do Idoso. Dispõe sobre a Política Nacional do Idoso. Cria o Conselho Nacional do Idoso e dá outras providências. Brasília, 1994. Disponível em: http://www.planalto.gov.br/ccivil_03/leis/18842.htm. Acesso em: 19 mar. 2019.

BRASIL. Ministério da Saúde. Portaria n. 1.395/GM/1999. Anuncia a Política Nacional da Saúde do Idoso. Brasília, 1999. Disponível em: http://crn3.org.br/Areas/Admin/Content/ upload/file0711201573034.pdf. Acesso em: 19 mar. 2019.

BRASIL. Lei $n$. 10.741, de $1^{\circ}$ de outubro de 2003. Estatuto do Idoso. Dispõe sobre o Estatuto do Idoso e dá outras providências. Brasília, 2003a. Disponível em: http://www.planalto. gov.br/ccivil_03/leis/2003/110.741.htm. Acesso em: 19 mar. 2019.

BRASIL. Secretaria Especial dos Direitos Humanos. Plano de ação internacional sobre o envelhecimento, 2002. Tradução: Arlene Santos. Brasília: Secretaria Especial dos Direitos Humanos, 2003b. 
BRASIL. Ministério da Saúde. Portaria n. 2.528, de 19 de outubro de 2006. Aprova a Política Nacional de Saúde da Pessoa Idosa. Brasília, 2006. Disponível em: http://bvsms.saude. gov.br/bvs/saudelegis/gm/2006/prt2528_19_10_2006.html. Acesso em: 19 mar. 2019.

BRASIL. Secretaria de Direitos Humanos da Presidência da República. Manual de enfrentamento à violência contra a pessoa idosa: é possível prevenir. É necessário superar. Brasília: SDH, 2014.

BRASIL. Emenda Constitucional n. 95, de 15 de dezembro de 2016. Altera o Ato das Disposições Constitucionais Transitórias para instituir o Novo Regime Fiscal e dá outras providências. Brasília, 2016. Disponível em: http://www.planalto.gov.br/ccivil_03/ constituicao/emendas/emc/emc95.htm. Acesso em: 27 nov. 2020.

BRASIL. Emenda Constitucional n. 103, de 12 de novembro de 2019. Altera o sistema de previdência social e estabelece regras de transição e disposições transitórias. Brasília, 2019. Disponível em: http://www.planalto.gov.br/ccivil_03/constituicao/emendas/emc/ emc103.htm. Acesso em: 27 nov. 2020.

DEPUTADOS congelam verba da saúde e educação por 20 anos. Carta Capital, 10 out. 2016. Disponível em: https://www.cartacapital.com.br/politica/deputados-congelamverba-da- saude-e-educacaopor-20-anos. Acesso em: 27 mar. 2018.

INSTITUTO BRASILEIRO DE GEOGRAFIA E ESTATÍSTICA (IBGE). Censo de 2010. Disponível em: https://censo2010.ibge.gov.br. Acesso em: 20 mar. 2019.

INSTITUTO BRASILEIRO DE GEOGRAFIA E ESTATÍSTICA (IBGE). Pesquisa Nacional por Amostra de Domicílios, 2012. Disponível em: https:/ww2.ibge.gov.br/home/estatistica/ populacao/trabalhoerendimento/pnad2012/default_s intese.shtm. Acesso em: 30 mar. 2019.

INSTITUTO BRASILEIRO DE GEOGRAFIA E ESTATÍSTICA (IBGE). Agência de notícias. Disponível em: https://agenciadenoticias.ibge.gov.br/agencia-noticias/2012-agenciadenoticias/noticias/20980-numero-de-idosos-cresce-18-em-5-anos-e-ultrapassa-30milhoesem-2017. Acessado em: 27 mar. 2019.

INSTITUTO BRASILEIRO DE GEOGRAFIA E ESTATÍSTICA (IBGE). Agência de notícias. Disponível em: https://agenciadenoticias.ibge.gov.br/agencia-sala-de-imprensa/2013agencia-denoticias/releases/24109-pnad-continua-taxa-de-desocupacao-e-de-12-4-etaxa-desubutilizacao-e-de-24-6-no-trimestre-encerrado-em-fevereiro-de-2019. Acesso em: 28 mar. 2019.

INSTITUTO BRASILEIRO DE GEOGRAFIA E ESTATÍSTICA (IBGE). Agência de notícias. Disponível em: https://agenciadenoticias.ibge.gov.br/agencia-noticias/2012-agenciadenoticias/noticias/23867-desemprego-sobe-e-atinge-12-7-milhoes-de-pessoas-aposdoistrimestres-de-queda. Acesso em: 28 mar. 2019. 
HADDAD, E.G. de M. O direito à velhice: aposentadoria e a previdência social. 2. ed. São Paulo: Cortez, 1993.

MARX, K.; ENGELS, F. Manifesto comunista. São Paulo: Boitempo, 2010.

TEIXEIRA, S. M. Envelhecimento do trabalhador e as tendências das formas de proteção social na sociedade brasileira. Argumentum, p. 63-77, 2010. Disponível em: https:// periodicos.ufes.br/argumentum/article/view/13. Acesso em: 28 nov. 2020.

\section{Sobre a autora}

Silvana Maria Escorsim - Doutora em Serviço Social. Professora adjunta. Câmara do Curso de Serviço Social, UFPR - Setor Litoral.

E-mail: mariaescorsim@ufpr.br 